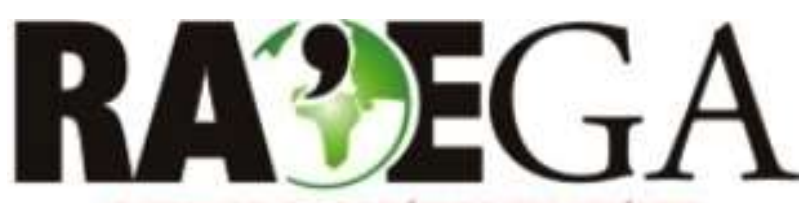

O ESPACO GEOGRÁFICO EM ANÁLISE

\title{
GESTÃO DOS RESÍDUOS SÓLIDOS URBANOS NA BACIA DO PARANÁ III: ELEMENTOS PARA UMA AGENDA DE PESQUISAS
}

\author{
URBAN SOLID WASTE MANAGEMENT IN THE PARANÁ III \\ RIVER BASIN: ELEMENTS FOR A RESEARCH AGENDA
}

\author{
Fábio de Oliveira Neves \\ Professor do Programa de Pós-graduação em Geografia \\ Universidade Estadual do Oeste do Paraná - UNIOESTE \\ Marechal Cândido Rondon, PR, Brasil \\ e-mail: foneves@gmail.com
}

Recebido em: 08/08/2015

Aceito em: 06/10/2016

\section{Resumo}

A gestão dos resíduos sólidos no Brasil necessita de reformas não só para adequar-se a política e plano nacionais do setor, como para avançar na busca de um sistema ambientalmente responsável, socialmente justo e economicamente sustentável. Idealizar uma gestão eficaz dos resíduos sólidos depende de atentar para as características locais e regionais. Neste artigo, propõe-se caracterizar o manejo dos resíduos sólidos nos municípios da Bacia Hidrográfica do Paraná III, em território brasileiro, já que este se tornou um recorte relevante para aplicação de políticas ambientais. O objetivo é de oferecer um panorama sobre a atual situação da gestão dos resíduos sólidos, contribuindo na formação de uma agenda de pesquisas. Os resultados indicam que a formação de uma agenda de pesquisas sobre os resíduos sólidos na Bacia do Paraná III não pode prescindir da consideração das seguintes características: a forte concentração da produção de resíduos em apenas três municípios (Cascavel, Foz do Iguaçu e Toledo); a expansão das empresas privadas no setor dos resíduos que se ocupam de $3 / 4$ da prestação de serviços; o papel dos catadores, sua organização e articulação; a elaboração e aplicação dos planos municipais de gestão dos resíduos sólidos; a ausência da gestão associada entre municípios; e o problema da destinação final nos municípios pequenos.

Palavras-chave: resíduos sólidos; agenda de pesquisas; serviços públicos. 


\begin{abstract}
The solid waste management in Brazil needs improvement not only to be adequate for the national policy and plan in the sector, but also seek for an environmentally responsible, socially fair and economically sustainable system. Idealizing an effective solid waste management depends on the local and regional characteristics. The aim of this article is to characterize the solid waste management in the Paraná III River Basin, in the Brazilian territory, considering that this area became relevant to the application of environmental policies. The goal is to present an overview on the solid waste management, contributing for the elaboration of a research agenda. The results show that a research agenda on the solid waste subject in Paraná III River Basin cannot do without the following characteristics: the high concentration of the waste generation in only three cities (Cascavel, Foz do Iguaçu and Toledo); the expansion of the private companies in the waste sector that provide $3 / 4$ of the services; the role of waste pickers, their organization and articulation; the elaboration and application of the solid waste local plans; the absence of associated waste management between the municipalities; and the waste final destination issue in the small municipalities.
\end{abstract}

Keywords: solid waste; research agenda; public services.

\title{
1. INTRODUÇÃO
}

A gestão dos resíduos sólidos no Brasil necessita de reformas não só para adequar-se a política e plano nacionais do setor, como para avançar na busca de um sistema ambientalmente responsável, socialmente justo e economicamente sustentável. Não basta minimizar a poluição ambiental com novas instalações, é necessário resolver os problemas sociais do trabalho com o lixo, considerando-se conjuntamente os setores formal e informal. Assim como não basta resolvê-los, se os serviços não se sustentam economicamente, seja com impostos ou taxas que permitam oferecer serviços públicos adequados às expectativas da população.

Idealizar uma gestão dos resíduos sólidos eficaz nas dimensões ambiental, social e econômica depende de conhecer a fundo as características locais e regionais.

O território nacional tem aproximadamente 8 milhões de $\mathrm{Km}^{2}$, onde encontra-se vasta diversidade de condições sociais, econômicas e ambientais. É necessário desenvolver estudos regionais que possam municiar os gestores 
públicos de dados, informações e reflexões mais adequadas a sua realidade territorialmente mais próxima. Adicionalmente, é preciso trabalhar com recortes que ultrapassem os limites político-administrativos dos municípios e sejam mais pertinentes ao tratamento de problemas ambientais, como é o caso das bacias hidrográficas.

A bacia hidrográfica tornou-se, a partir da Constituição Federal de 1988, a base para o planejamento regional. A partir desse fato, destacaram-se 0 conceito de gestão da bacia hidrográfica e criaram-se Comitês de Bacias Hidrográficas como instância descentralizada e participativa de discussão (LIMA, 2005).

Esse recorte espacial, que já era relevante nos estudos das ciências naturais e da Geografia Física, passou também a ser objeto de estudo para as ciências sociais e humanas, pois se configurou como território de planejamento e gestão delimitado mais pelo aspecto físico-natural do que pelos limites político-administrativos da federação brasileira. "Recorte que nasce de uma abordagem naturalista, geossistêmica, mas assume um novo significado quando a sociedade a individualiza em função de seus interesses e define nesse espaço um sistema de ações e objetos criados que devem estar em equilíbrio com o sistema natural." (LIMA, 2005, p. 180).

Neste artigo, propõe-se caracterizar o manejo dos resíduos sólidos na Bacia Hidrográfica do Paraná III, no território brasileiro, já que este se tornou um recorte relevante para aplicação de políticas no Oeste do estado do Paraná. Trata-se de definir possíveis focos para o desenvolvimento de estudos regionais sobre a gestão de resíduos sólidos, assim como de apresentar um quadro atual e resumido do manejo dos resíduos na área de estudo.

A Bacia do Paraná III está situada na fronteira entre Brasil e Paraguai, tendo como referência os afluentes do Rio Paraná que desembocam no Lago de Itaipu e na confluência deste rio com o Iguaçu. Em território brasileiro, a 
bacia hidrográfica engloba 29 municípios, que abrangem uma área de aproximadamente $15 \mathrm{mil} \mathrm{km}^{2}$, e cerca de um milhão de habitantes (Figura 1).

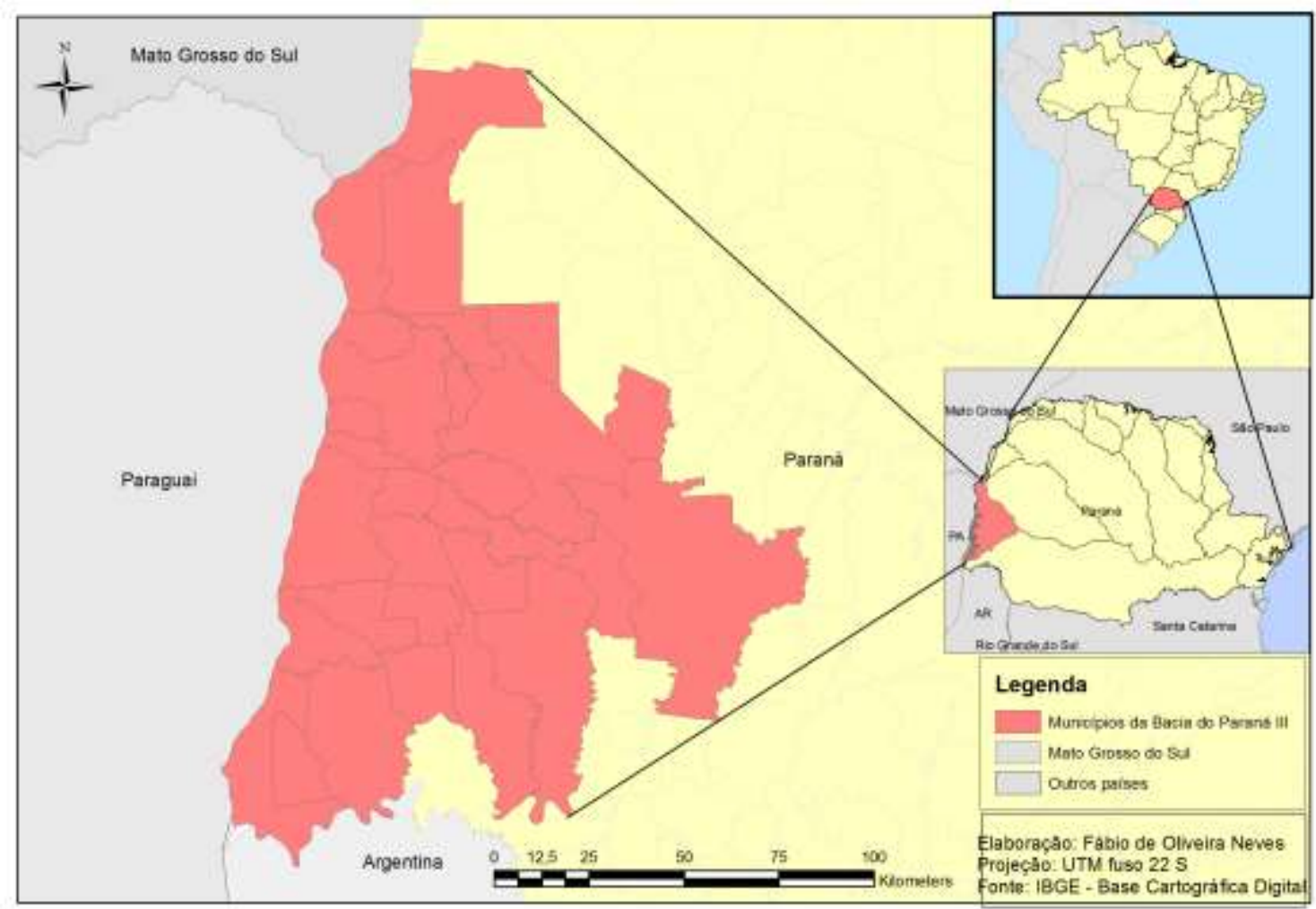

Figura 1: Mapa de localização dos municípios que compõe a Bacia do Paraná III em território brasileiro

A finalidade deste artigo é oferecer um panorama das características da gestão dos resíduos sólidos urbanos na área de estudo, contribuindo na formação de uma agenda de estudos. Os dados apresentados são organizados e tratados a partir do Diagnóstico do Manejo dos Resíduos Sólidos Urbanos (DMRSU) de 2013 (SNSA, 2015) ${ }^{1}$, que integra o Sistema Nacional de

\footnotetext{
${ }^{1}$ As limitações do DMRSU referem-se, principalmente, às possibilidades de informações erradas declaradas por prefeituras e demais órgãos concernentes. Embora, haja duas etapas de correção de dados e inconsistências, conforme declarado nos aspectos metodológicos da pesquisa, é plausível que os problemas de informações erradas não sejam totalmente eliminados. Supõe-se que esses problemas resultam de desconhecimento técnico e terminológico ou mesmo por fins políticos, para esconder falhas da administração pública. Mesmo com essas ressalvas, o diagnóstico é o documento mais atualizado e amplo disponível do setor. A pesquisa, em 2013 , englobou $64,1 \%$ dos municípios brasileiros e $80,8 \%$ da população total do país (SNSA, 2015). Somente um município da área de estudo não participou do diagnóstico: Terra Roxa.
} 
Informações sobre Saneamento Ambiental (SNIS). Trata-se de informações fornecidas pelas prefeituras e órgãos responsáveis pelo setor em cada município. Utiliza-se também dados do Instituto Ambiental do Paraná, instituição responsável pela emissão de licenças ambientais sobre as unidades de destinação final de resíduos sólidos urbanos.

\section{GESTÃO DOS RESÍDUOS SÓLIDOS URBANOS NO BRASIL: PREMISSAS E CARACTERÍSTICAS}

A gestão dos resíduos sólidos no Brasil, sob responsabilidade dos municípios, é composta de diferentes etapas. Em geral, a montante está a coleta e a jusante a destinação final ou eliminação. As etapas intermediárias referem-se, comumente, a tipos de triagem de materiais e tratamentos alternativos à eliminação, como a reciclagem e a compostagem.

Neste artigo, acredita-se que a última etapa, a destinação final ou eliminação, é a que determina o formato de todo o sistema, das necessidades da coleta e dos tipos de tratamento. "Ce n'est plus la collecte qui determine l'ensemble de la chaîne de gestion, mais désormais l'aval (le stockage contrôlé) qui peut également avoir um impact sur les choix de gestion à l'amont." (CAVÉ et al., 2015, p. 23). Assim, estas reflexões iniciam-se pela etapa de destinação final.

A matriz de destinação final brasileira é indiscutivelmente o aterramento: cerca de $80 \%$ dos resíduos sólidos urbanos coletados são "eliminados" com esse método ${ }^{2}$. Quase a metade das unidades de destinação final por aterramento são lixões, contra pouco mais de $1 / 4$ de aterros controlados e $1 / 4$ de aterros sanitários (Figura 2).

\footnotetext{
${ }^{2}$ As unidades de aterramento no Brasil são classificadas em lixões ou vazadouros a céu aberto; aterros controlados e aterros sanitários. Eles diferenciam-se pela preparação da área para contenção da poluição ambiental proveniente da disposição dos resíduos. Enquanto o lixão não possui medidas para esse fim e o aterro controlado tem medidas mínimas, como a cobertura dos resíduos por camadas de terra e compactação, o aterro sanitário possui impermeabilização de base, drenagem e tratamento de líquidos percolados e gases (FEAM, 2006).
} 
O aterramento, por si só, não é um problema. É o tipo de destinação final com menor custo e que tende a ser adotado em países territorialmente extensos, enquanto a incineração tende a ser adotada em países com baixa disponibilidade de terras (GAILLOCHET, 2009). Os incineradores são uma opção de maior custo e adaptada a áreas conurbadas e grandes metrópoles, ao contrário dos aterros sanitários que dependem da expansão da área utilizada.

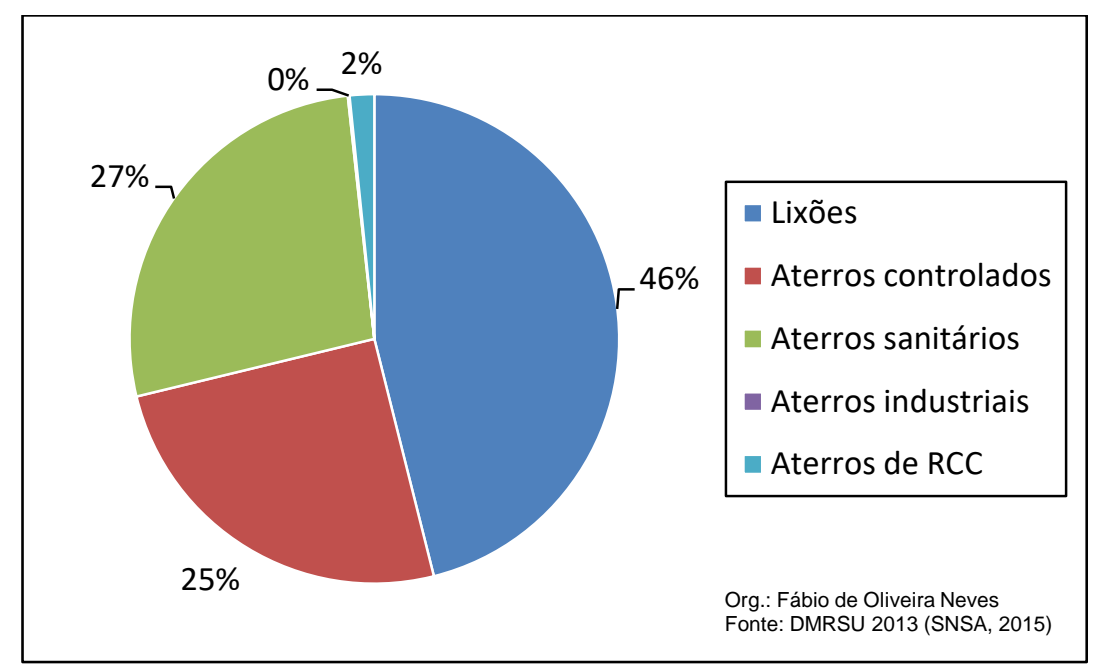

Figura 2: Percentual de unidades de destinação final no Brasil em 2013

Com relação aos riscos de poluição, há certa controvérsia na comparação entre os dois métodos. Bolognesi (2012) contesta a ideia de que as modernas usinas incineradoras são mais poluentes que os aterros sanitários, pois nestes, mesmo com a drenagem e queima ou aproveitamento do biogás, haveria maior liberação na atmosfera devido à impossibilidade de drenagem em toda a massa aterrada.

A polêmica entre a "melhor" matriz de destinação final de resíduos sólidos urbanos não se esgota facilmente e depende das características de cada localidade e de cada país (disponibilidade de recursos financeiros e técnicos, composição dos resíduos, tipos de tratamento, qualidade do serviço 
de coleta indiferenciada e seletiva, hábitos dos usuários destes serviços, disponibilidade de área, etc.).

A qualidade dos serviços prestados nas etapas da gestão, não somente na destinação final, varia fortemente conforme a localização e as grandes regiões do país. Dos 1.196 lixões levantados pela pesquisa, mais da metade concentra-se no Nordeste. O Sul e o Sudeste juntos concentram 13,3\% dos lixões, enquanto o Centro-Oeste, o Nordeste e o Norte englobam 86,7\% (Figura 3). Este resultado expõe a dimensão das desigualdades regionais que marcam a etapa da destinação final.

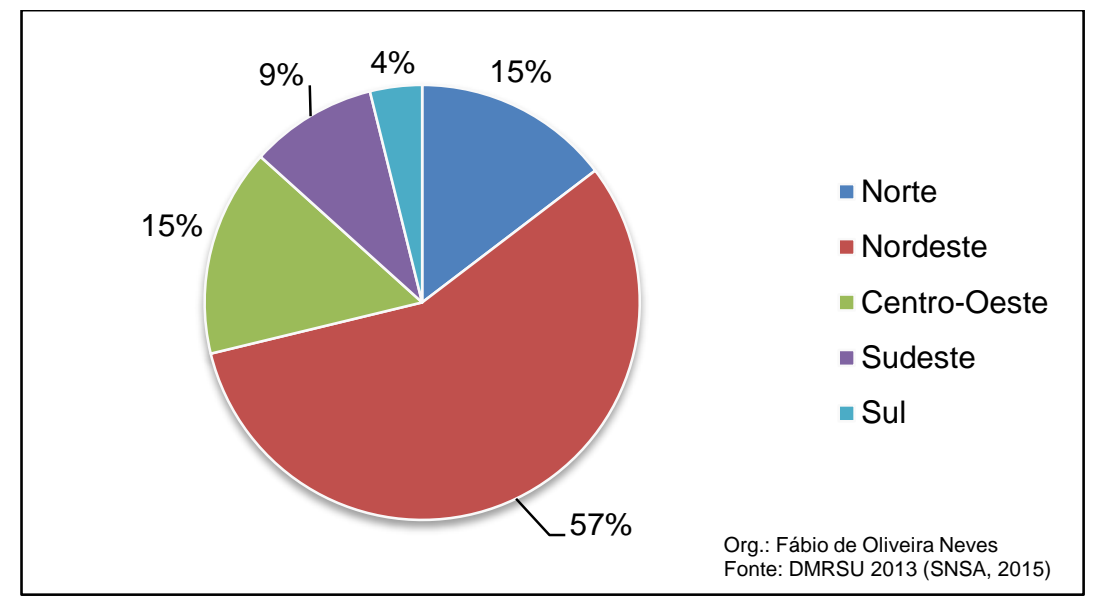

Figura 3: Percentual de lixões por grande região no Brasil em 2013

A valorização pós-consumo é uma etapa intermediária entre a coleta e a eliminação, com base na concepção do resíduo sólido enquanto recurso, seja material (resultando em matérias-primas provenientes da reciclagem ou de adubo de compostagem), seja energético (com a geração de energia elétrica ou calorífica).

O tipo mais adequado de valorização depende diretamente da composição dos resíduos sólidos. As altas taxas de umidade no lixo de países de baixa e de média renda, como o Brasil, justificam a melhor adequação da compostagem como tratamento em comparação à valorização energética 
(CAVÉ et al., 2015). A reciclagem de embalagens torna-se importante na formação de uma economia circular e na reinserção de materiais no ciclo produtivo, podendo ser acompanhada da criação de postos de trabalho.

No Brasil, a valorização, tanto por reciclagem, quanto por compostagem, ainda é deficiente. A compostagem de resíduos orgânicos é uma incógnita: apenas $0,1 \%$ dos resíduos coletados são direcionados a unidades de compostagem (Figura 4).

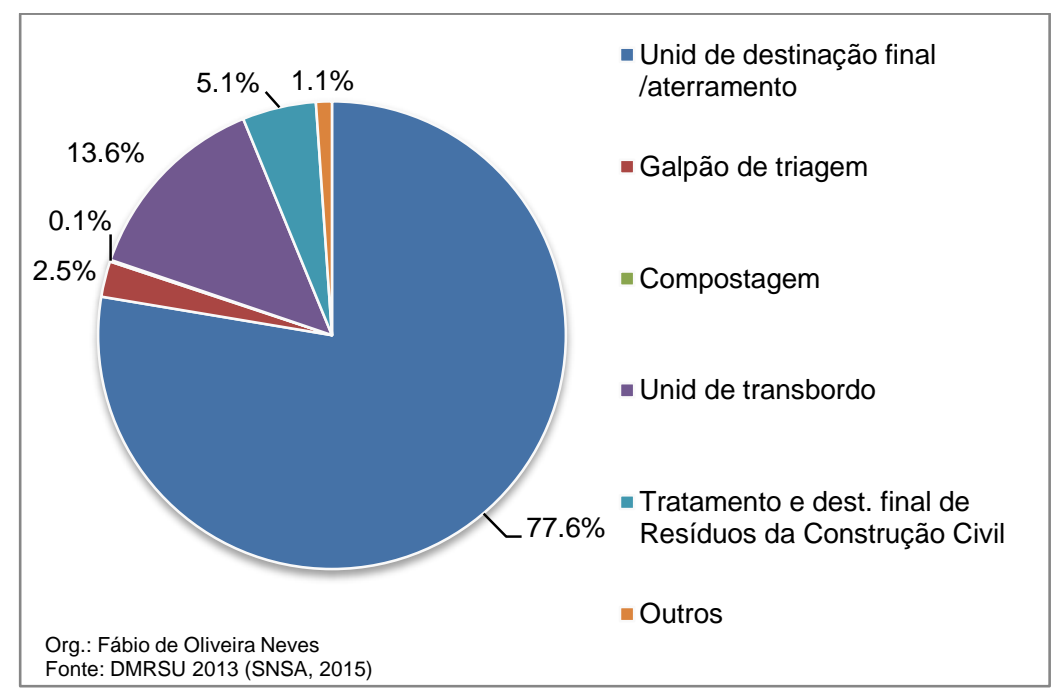

Figura 4: Percentual de resíduos recebidos por tipo de unidade de processamento no Brasil em 2013

Apesar de o país ser líder na reciclagem de elementos específicos (plásticos, PETs e latas de alumínio para bebidas), as unidades de triagem recebem apenas 2,5\% dos resíduos sólidos coletados, o que indica a pequena magnitude da reciclagem promovida pelo poder público no país. Bosi (2008) atribui a expansão histórica da reciclagem no Brasil não ao serviço público municipal de coleta seletiva e triagem de materiais recicláveis, mas à competitividade alcançada no mercado por esses materiais (em comparação com as matérias-primas tradicionais) graças ao baixo custo da força de trabalho dos catadores. 
Supõe-se, consequentemente, que os bons resultados pontuais na valorização por reciclagem dependem de ações do setor privado, de um circuito de catadores autônomos, sucateiros e atravessadores que concentram suas atividades nos elementos mais rentáveis para o retorno à cadeia produtiva (como o alumínio). Nesse sentido, é indispensável considerar a ação desses atores "informais" nos processos de valorização pós-consumo dos resíduos sólidos urbanos. Pierrat (2011) defende que a melhoria nesses processos depende da complementação entre a triagem "oficial" e as filiais informais de recuperação em países do Sul.

Antes de quaisquer reformas que visem reverter esse quadro territorialmente desigual e qualitativamente limitado, é importante considerar algumas premissas. A primeira refere-se às limitações da ação do Estado e mais especificamente das prefeituras.

O setor público isoladamente não parece capaz de oferecer soluções definitivas para os problemas decorrentes do manejo dos resíduos sólidos. As soluções para esse sistema não são exclusivamente técnicas. Cada vez mais, o fator social destaca-se como uma variável, pelo potencial de conflito entre atores interessados no setor. Há conflitos e resistência às instalações de manejo do lixo (unidades de destinação final, transbordo, triagem, etc.) pelas populações em suas vizinhanças.

As ideologias sustentáveis ganham voz na atuação de ONGs e demais grupos que defendem soluções que não são as mesmas de uma perspectiva técnico-econômica.

O comportamento e a participação popular na separação dos resíduos para a coleta seletiva tornam-se primordiais e requerem conhecimento sobre a população, seu cotidiano e hábitos. A centralidade do indivíduo nos sistemas de gestão dos resíduos sólidos urbanos afirmou-se (BARBIER, 2002). Cidadão, consumidor, morador e usuário tornaram-se categorias progressivamente solicitadas no manejo dos resíduos sólidos (ROCHER, 2006).

Os esforços a favor da prevenção, da reciclagem e da compostagem dos resíduos sólidos também depende de uma forte base de conhecimento sobre 
as práticas sociais nas duas pontas da cadeia do lixo: o consumo (tanto o doméstico, quanto o industrial) e o pós-consumo (o retorno das embalagens, produtos e materiais recicláveis para a cadeia produtiva com a logística reversa, a produção de energia e de matérias-primas provenientes da reciclagem).

O problema social da catação, do trabalho precário dos catadores de rua, da geração de renda para famílias pobres e do trabalho infantil também chama atenção e insere a responsabilidade social como uma demanda dirigida aos gestores.

O fator social passa a constituir, portanto, parte integrante de uma agenda de estudos da gestão dos resíduos sólidos, não só para a Geografia, como para outras ciências humanas.

As empresas, por sua vez, são chamadas a executar "ações sustentáveis" e demonstrar uma atitude ambientalmente responsável diante de seus consumidores. Elas também podem participar e financiar projetos de meio ambiente. O setor de prestação de serviços ligados ao meio ambiente e, especificamente, ao manejo dos resíduos sólidos, é outro foco de ação das empresas privadas.

A cooperação com o setor privado seja com empresas, ONGs e/ou organizações de catadores surge como condição sem a qual as reformas teriam um potencial bem restrito e, portanto, distante de atender as demandas ambientais. Portanto, a cooperação com o setor privado torna-se outro elemento central da agenda de estudos do setor.

A segunda premissa a ser considerada é a adequação do arcabouço legislativo que possibilite as reformas necessárias, como, por exemplo, a criação de leis ambientais aplicáveis em áreas urbanas.

A Lei 12.305/2010, que institui a Política Nacional dos Resíduos Sólidos (PNRS), representa um avanço na medida em que norteia as reformas do setor, dando um direcionamento tanto aos programas que partem dos governos estaduais, quanto às ações promovidas pelos municípios. A exigência dos planos estaduais e municipais também configura um avanço, pois insere 
formalmente a perspectiva do planejamento de médio e longo prazo e das metas a serem alcançadas na agenda do meio ambiente. A PNRS reconhece os resíduos sólidos como um material com valor econômico e social, reforçando a importância da atividade dos catadores (RUTKOWSKI \& RUTKOWSKI, 2015).

As leis e os regulamentos constituem, desse modo, mais um tema incontornável para a criação de uma agenda de estudos dos resíduos sólidos.

A terceira premissa refere-se aos entraves políticos às reformas do setor. A política urbana é afetada pelo poder de agentes relevantes, como os agentes imobiliários e proprietários fundiários que podem ter interesses conflitantes com os ideais da sustentabilidade ambiental. A disputa entre grupos de interesse pode dificultar a aprovação de leis e o estabelecimento de políticas ambientais. Nesse sentido, é importante compreender o conjunto de atores e grupos de interesse que integram as questões ambientais e considerar na agenda de estudos do setor o tema da governança do ambiente urbano que se supõe que seja progressivamente mais participativa e democrática.

A quarta premissa é a barreira dos limites territoriais no trato das questões ambientais. Por vezes, o enfrentamento dos problemas ambientais está sujeito aos recortes políticos do território, ao limite entre municípios ou entre estados, dificultando a tomada de decisões e as ações em conjunto. $O$ isolamento do município também pode ser visto como uma limitação no trato desses problemas. Nesse contexto, existem alguns instrumentos que podem ser utilizados como alternativas, como: os comitês de bacias hidrográficas, os consórcios intermunicipais e a gestão associada entre municípios.

No caso de municípios sem meios técnicos e financeiros para a melhoria do sistema de manejo dos resíduos sólidos, o recurso à gestão associada pode racionalizar a execução dos serviços públicos e possibilitar a instalação de novos equipamentos para as etapas de tratamento e destinação final do lixo.

Por fim, é preciso enfatizar que a gestão dos resíduos sólidos depende de considerar a diversidade de instituições interessadas no setor, assim como o jogo de escalas em que estas instituições atuam: do 
local ao regional, do nacional ao internacional. A ausência de conhecimento ou a simples negação desses elementos interdependentes limitam a construção de uma agenda de estudos no setor.

As reflexões sobre a gestão dos resíduos sólidos também carecem de conhecer alguns fatos relevantes para a composição da agenda de estudos.

As parcerias público-privadas (PPPs) para os serviços ambientais urbanos é um objeto de estudo a ser continuamente analisado, pois se trata de um fato da gestão pública a partir das duas últimas décadas do século $X X$. A gestão dos resíduos sólidos no está caracterizada pelo progresso da delegação de serviços ambientais a empresas privadas, isto é, a terceirização dos serviços de limpeza pública e das operações de destinação final/eliminação de resíduos sólidos urbanos. Há, conforme os dados da Pesquisa Nacional de Saneamento Básico (IBGE, 2010), uma forte inserção da iniciativa privada na prestação de serviços ligados ao lixo na Região Sul do país.

O crescimento da participação das empresas privadas no setor de limpeza pública é fato destacado ao menos nos últimos 15 anos (ANDRADE \& FERREIRA, 2011). O discurso sob o qual se justifica o recurso às empresas privadas prestadoras de serviços baseia-se nas falhas do sistema público na contratação de pessoal e na aquisição de máquinas e demais bens (um argumento do New Public Management ${ }^{3}$ ). Assim, são postos em prática regimes de delegação ou concessão de serviços visando melhorar a qualidade destes. Ressalta-se que o poder público local não se desonera da responsabilidade do setor, pois é o gestor final e responsável pela destinação dos resíduos produzidos em seu território, mesmo que os serviços estejam sob a execução de parceiros privados.

O segundo fato a ser destacado é o processo de empowerment dos atores sociais do meio ambiente urbano e em diferentes escalas. $O$

\footnotetext{
${ }^{3}$ O New Public Management é um movimento de crítica à gestão pública do século XX. Inspirase nos governos neoliberais do Presidente Reagan nos Estados Unidos e da Primeira Ministra Margareth Tatcher no Reino Unido para desenvolver um discurso crítico ao Estado que não teria eficiência técnica e recursos financeiros para atender aos cidadãos desejosos de serviços públicos mais eficientes.
} 
empowerment significa o crescimento da capacidade de indivíduos e grupos de se engajar, influenciar e tornar mais transparente as ações de instituições que os afetam (BENNET, 2002 apud TREMBLAY \& GUTBERLET, 2012).

Esse processo se desenvolve em diferentes escalas, por diferentes atores. Os usuários dos serviços formam ONGs e associações visando defender seus interesses. As empresas surgem como parceiros privilegiados do Estado na prestação de serviços públicos. No Brasil, outro ator vem desenvolvendo um processo consistente de empowerment: os catadores.

Os catadores se organizam, em escala local, com o apoio de outras instituições e do poder público, em associações ou cooperativas. Esse processo iniciou-se no final da década de 1980 e início da década de 1990, quando surgiram associações e cooperativas em algumas capitais e outras cidades brasileiras: a Associação de Catadores de Materiais de Porto Alegre; a Cooperativa de Catadores Autônomos de Papel, Aparas e Materiais Reaproveitáveis (COOPAMARE) em São Paulo; a Associação de Carroceiros no Município de Canoas-RS; a Associação dos Catadores de Papel, Papelão e Material Reciclável (ASMARE) de Belo Horizonte; entre outras.

Os programas de coleta seletiva solidária (modelo de cooperação entre município e catadores no Brasil) auxiliaram no empowerment desses atores sociais. Nesses programas, o município contrata as cooperativas de catadores como um operador formal do sistema de resíduos sólidos municipais (RUTKOWSKI \& RUTKOWSKI, 2015). As cooperativas atuam com o seu savoir-faire sobre os resíduos classificados como "secos", realizando a coleta seletiva, a triagem e o beneficiamento primário dos materiais recicláveis 4 .

As associações e cooperativas contribuem para a melhoria da visibilidade do catador como ator social, na medida em que organizam seu trabalho, identificam seus integrantes, estabelecem parcerias com outras organizações e com o poder público, entre outras ações. Também é uma forma de combater a precarização do trabalho, de reduzir a vulnerabilidade diante do

\footnotetext{
${ }^{4} \mathrm{O}$ beneficiamento primário corresponde à separação de materiais por cor e material, prensagem, enfardamento e armazenamento para posterior venda. Geralmente, esse processo é realizado em galpões de triagem.
} 
mercado e de tentar aumentar a renda pela negociação direta do produto recuperado com os compradores (IKUTA, 2010; MEIRA et al., 2007).

$\mathrm{Na}$ escala supralocal, os catadores se organizam através da criação de redes para melhorar as condições para comercialização e beneficiamento de recicláveis, com apoio do poder público, como no programa federal Cataforte ${ }^{5}$.

É necessário ressaltar também a organização dos catadores enquanto movimento social - O Movimento Nacional de Catadores de Materiais Recicláveis (MNCR). Este tem seu ponto de partida na ocorrência de fóruns de discussão sobre os problemas do trabalho no lixo (o Fórum Lixo e Cidadania), dando origem a encontros e um congresso nacional de catadores de recicláveis. A formação do MNCR permitiu a apresentação de demandas para os poderes públicos, assim como a troca de informações entre as organizações locais de catadores.

The joint work of these two movements has brought the social and economic inclusion of the previously invisible informal recycling workers to the political attention of the Federal government and the governments of many Brazilian States. (RUTKOWSKI \& RUTKOWSKI, 2015, p. 1085).

Ao considerar tais fatos para a composição da agenda de estudos do setor, é necessário voltar-se para a Bacia do Paraná III, com o objetivo de elaborar um diagnóstico da situação atual da gestão dos resíduos sólidos urbanos e refletir sobre condições apresentadas.

\section{GESTÃO DE RESíduOS SÓlIDOS URBANOS NA BACIA DO PARANÁ III: UMA APROXIMAÇÃO}

A Bacia do Paraná III engloba integralmente ou parcialmente o território de 29 municípios, que podem ser divididos em três grupos. O grupo 1 é constituído pelos maiores municípios em porte populacional e na produção de

\footnotetext{
${ }^{5}$ Trata-se de um programa de inclusão social do governo federal, com um aporte financeiro de 60 milhões de reais para quatro anos, com o objetivo de criar e organizar 35 redes de cooperativas de catadores para fortalecer sua capacidade de funcionamento (RUTKOWSKI \& RUTKOWSKI, 2015).
} 
resíduos. Constitui-se de Toledo, Cascavel e Foz do Iguaçu. Os primeiros são contíguos territorialmente e possuem aproximadamente 130.000 e 300.000 habitantes, respectivamente. O último tem aproximadamente 260.000 habitantes. O grupo 2 constitui-se de 12 municípios com população entre 10.000 e 50.000 habitantes. O terceiro é formado pelos menores municípios em porte populacional: 14 no total, que possuem menos de 10.000 habitantes $^{6}$ (Figura 5).

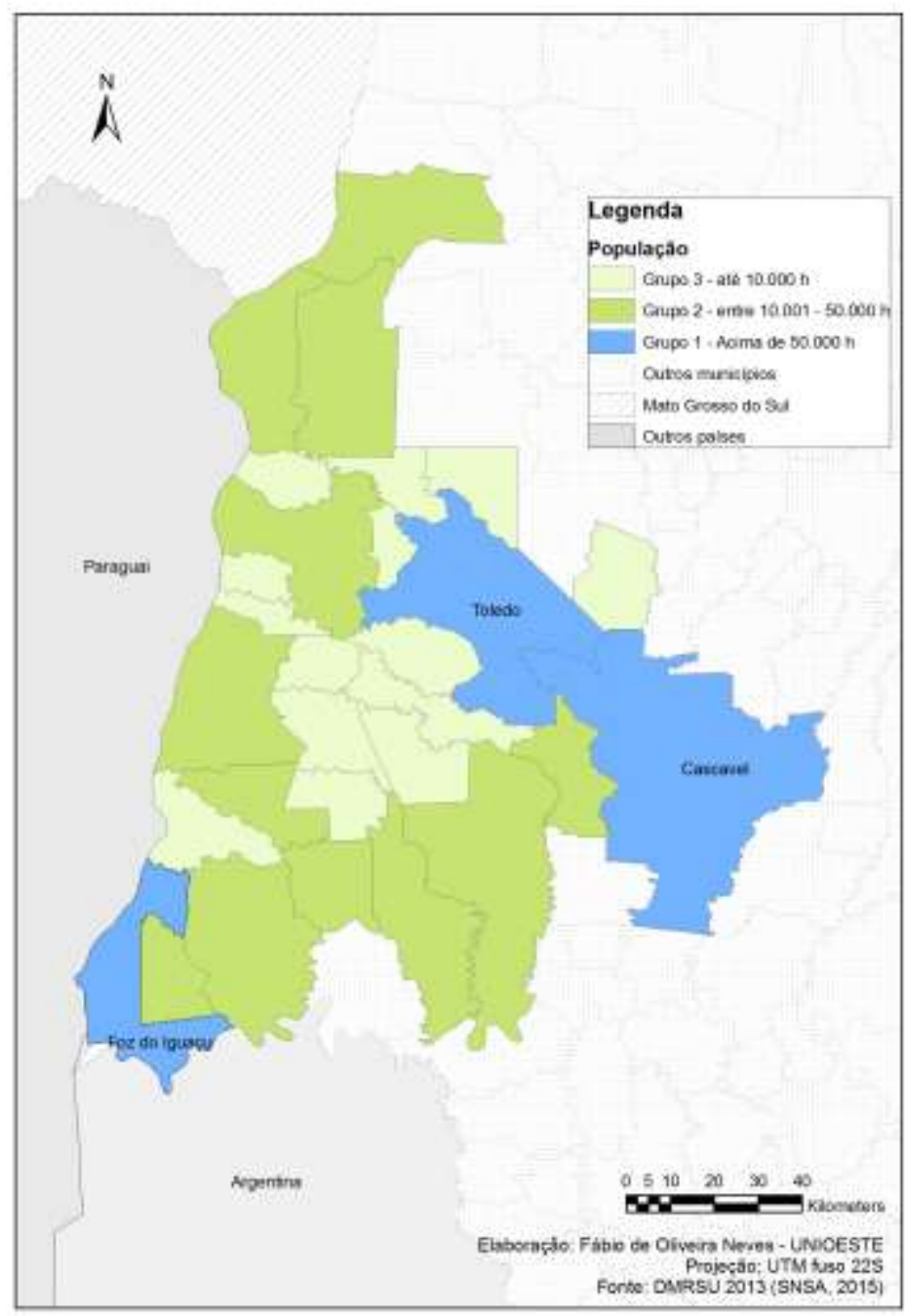

\footnotetext{
${ }^{6}$ Grupo 1: Cascavel, Foz do Iguaçu e Toledo. Grupo 2: Altônia, Céu Azul, Guaíra, Marechal Cândido Rondon, Matelândia, Medianeira, Missal, Santa Helena, Santa Tereza do Oeste, Santa Terezinha de Itaipu, São Miguel do Iguaçu e Terra Roxa. Grupo 3: Diamante D'Oeste, Entre Rios do Oeste, Itaipulândia, Maripá, Mercedes, Nova Santa Rosa, Ouro Verde do Oeste, Pato Bragado, Quatro Pontes, Ramilândia, São José das Palmeiras, São Pedro do Iguaçu, Tupãssi e Vera Cruz do Oeste.
} 
Figura 5: Municípios da Bacia do Paraná III segundo faixa populacional -2013

A quantidade de resíduos sólidos coletados nos indica o peso de cada grupo de municípios no sistema de gestão de resíduos da bacia. Os três municípios do grupo 1 são responsáveis pelo total de $3 / 4$ dos resíduos coletados. E os 14 municípios com menos de 10.000 habitantes respondem apenas por $6 \%$. A situação da gestão dos resíduos sólidos na área de estudo depende fortemente do manejo que é realizado no grupo 1, que possui um forte impacto ambiental e econômico no setor (Figura 6).

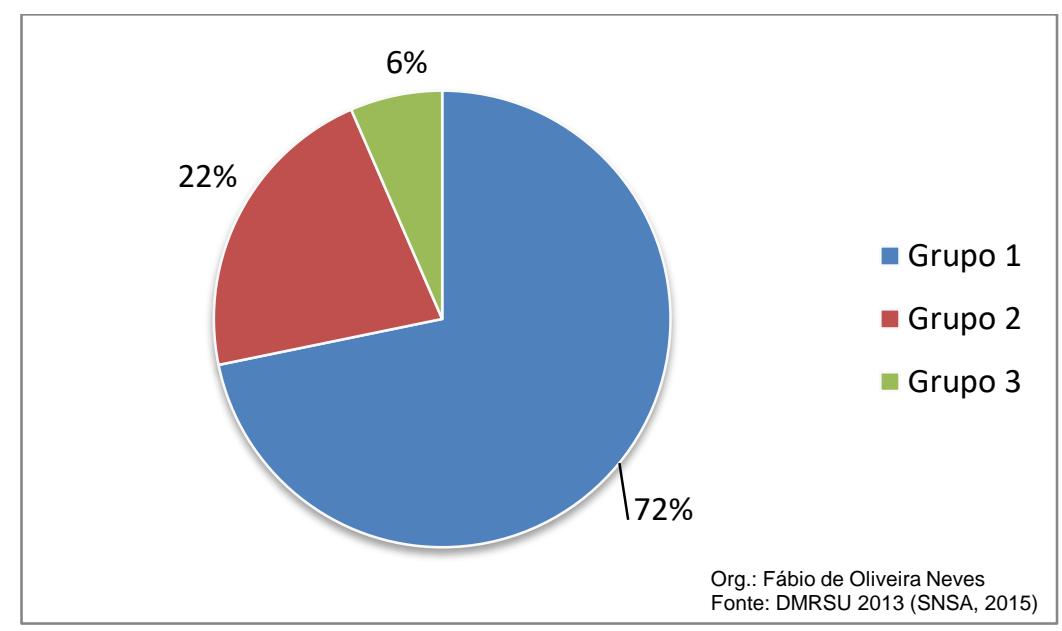

Figura 6: Percentual de resíduos coletados segundo grupo de municípios da Bacia do Paraná III - 2013

Retomando a premissa de que o poder público por si só não parece capaz de apresentar as soluções definitivas para os problemas ambientais, pode-se questionar qual é o atual papel das prefeituras no serviço básico de coleta de lixo urbano, quais são os principais parceiros e quais são os resultados desse serviço.

A coleta do lixo urbano demonstra bons resultados na Bacia do Paraná III: atende-se aproximadamente $99 \%$ da população urbana. Trata-se da quase universalização do serviço, uma condição para o bom funcionamento de todo o sistema, incluindo as etapas de tratamento e destinação final/eliminação. 
A inserção das empresas prestadoras de serviço no setor é considerável. Elas respondem $3 / 4$ do total dos resíduos urbanos coletados na Bacia do Paraná III. Elas atuam em 16 municípios e são agentes executores majoritários da coleta em 11 deles. As prefeituras, por sua vez, recolhem 16\% do lixo urbano. Em 16 municípios, a prefeitura é o agente executor de maior importância.

O grupo 1, dos maiores municípios, terceirizou a coleta e só conta com empresas ou com empresas e catadores na execução do serviço. Nos demais grupos não há um padrão definido. Há empresas atuando em 16 municípios. Somente dois, com menos de 10.000 habitantes, declararam que a prefeitura é a única executora da coleta (Figura 7$)^{7}$.

\footnotetext{
${ }^{7}$ Terra Roxa não participou do DMRSU 2013.
} 


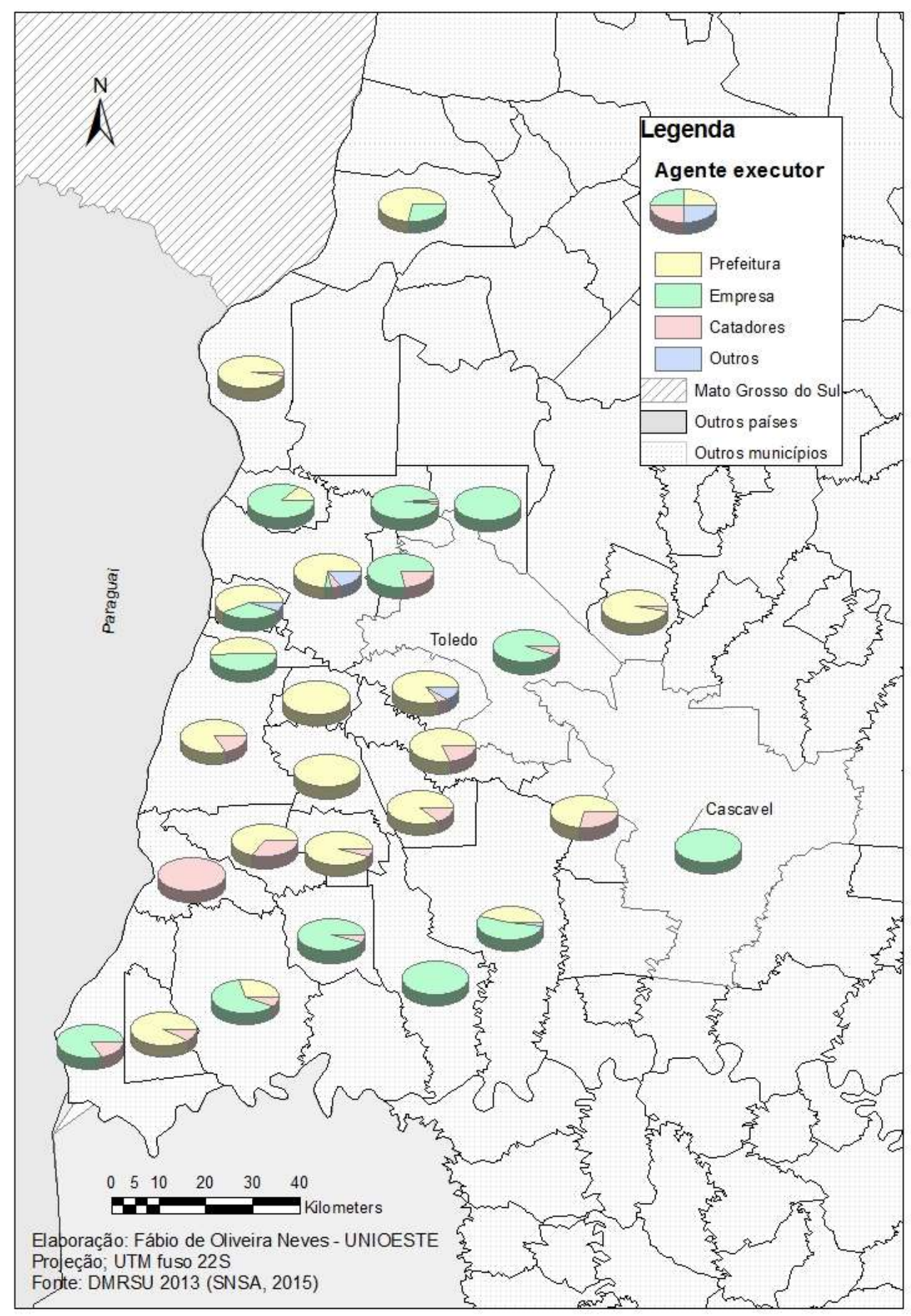

Figura 7: Instituições que executam a coleta de resíduos sólidos por município na Bacia do Paraná III - 2013

Confirma-se que, seguindo o modelo liberal de gestão, apresentado em Neves (2013), o poder público tende a manter-se como gestor e fiscalizador 
dos serviços públicos delegados ou concedidos a terceiros através das PPPs. No caso do modelo que vem se formando no Brasil, as PPPs tendem a ser realizadas majoritariamente com empresas privadas, porém, não excluem outros atores, como os catadores. O Brasil tem se caracterizado como líder nos países em desenvolvimento em facilitar o envolvimento público e as parcerias com o setor privado na gestão dos resíduos sólidos (KRULJAC, 2012).

Na Bacia do Paraná III, os catadores têm responsabilidades com a coleta em 19 municípios, sendo responsáveis por 8\% do total dos resíduos coletados na área de estudo. Constituem, portanto, um dos principais parceiros do poder público para o setor e estão envolvidos diretamente com a coleta seletiva e o beneficiamento de materiais para a reciclagem. Segundo Rutkowski \& Rutkowski (2015), a integração dos catadores no sistema de resíduos sólidos municipal no Brasil: incrementa as taxas de reciclagem; resulta em menor custo comparado à contratação de empresas convencionais; melhora a qualidade dos materiais e a eficiência da coleta seletiva; possibilita maior inclusão dos filhos dos catadores nas escolas; melhora as condições de trabalho dos catadores; e minimiza impactos negativos da reciclagem informal, como a poluição e os riscos à saúde e à segurança da atividade dos catadores.

Os programas de coleta seletiva estão presentes na quase totalidade dos municípios da Bacia do Paraná $\mathrm{II}^{8}$. As maiores quantidades coletadas estão nos dois maiores: aproximadamente 7.000 toneladas em Cascavel e 20.000 toneladas em Foz do Iguaçu no ano de 2013. É interessante notar que a coleta seletiva se organiza de forma e com parceiros distintos.

Em Cascavel, o programa de coleta seletiva municipal está sob a execução de uma empresa privada. A parceria com os catadores organizados do município que marcou o lançamento do premiado Programa Ecolixo, no início da década de 2000, foi enfraquecida. Em 2011, existia um acordo que garantia que a totalidade dos serviços de coleta seletiva e beneficiamento de recicláveis fosse realizada pela Cooperativa de Catadores de Materiais

\footnotetext{
${ }^{8}$ São José das Palmeiras não possui coleta seletiva. O município de Terra Roxa não apresentou dados no DMRSU 2013.
} 
Recicláveis de Cascavel (COOTACAR). Esse acordo foi rompido em 2011, e a coleta seletiva terceirizada. Restou a COOTACAR ficar com parte do recebimento de materiais recicláveis proveniente principalmente de empresas e instituições públicas para triagem e comercialização ${ }^{9}$.

Em Foz do Iguaçu, pelo contrário, a parceria com os catadores se fortaleceu. Mesmo considerando que há uma relevante população flutuante no município pelo turismo, as 20.000 toneladas recolhidas para reciclagem, principalmente pelos catadores, destacam-se. A Cooperativa de Agentes Ambientais de Foz do Iguaçu (COAAFI) é responsável pela maior parte do serviço e desenvolveu-se com apoio direto da empresa Itaipu Binacional no contexto do Programa Coleta Solidária ${ }^{10}$.

Acredita-se que esse programa, voltado ao apoio dos catadores na Bacia do Paraná III, teve um impacto regional considerável não só pelo auxílio direto na formalização de organizações dos catadores, como também pelos treinamentos e cursos de capacitação. Atualmente, há associações ou cooperativas de catadores em 18 municípios da Bacia do Paraná III. A criação dessas organizações faz parte da busca do empowerment dos catadores enquanto atores urbanos e do meio ambiente local. Ainda assim, trata-se de um processo complexo que depende do estabelecimento de parcerias com as prefeituras e do apoio de agentes externos.

O problema social dos catadores, contudo, não se resume apenas à formação de associações de catadores, pois estas não conseguem atrair a maior parte dos catadores autônomos. Nas associações e cooperativas de catadores de Toledo, Cascavel e Foz do Iguaçu há o relato dos seus representantes da dificuldade em integrar catadores dispersos/desorganizados, por razões diversificadas: como a falta de cultura associativa, a dificuldade de

\footnotetext{
${ }^{9}$ Relato presente em Neves (2013).

${ }^{10}$ O Programa Coleta Solidária originou-se da reestruturação de outro programa antigo no município: o Foz Recicla. Esse programa tornou-se referência para outros municípios da região, com apoio da Itaipu Binacional.
} 
cumprir regras, a relação de dependência com atravessadores e sucateiros, entre outras $^{11}$.

Com relação às condições de disposição final na Bacia do Paraná III, adotam-se, nesse artigo, as informações sobre a disposição de resíduos sólidos urbanos para o Estado do Paraná de 2012 divulgadas pelo IAP (Figura 8).

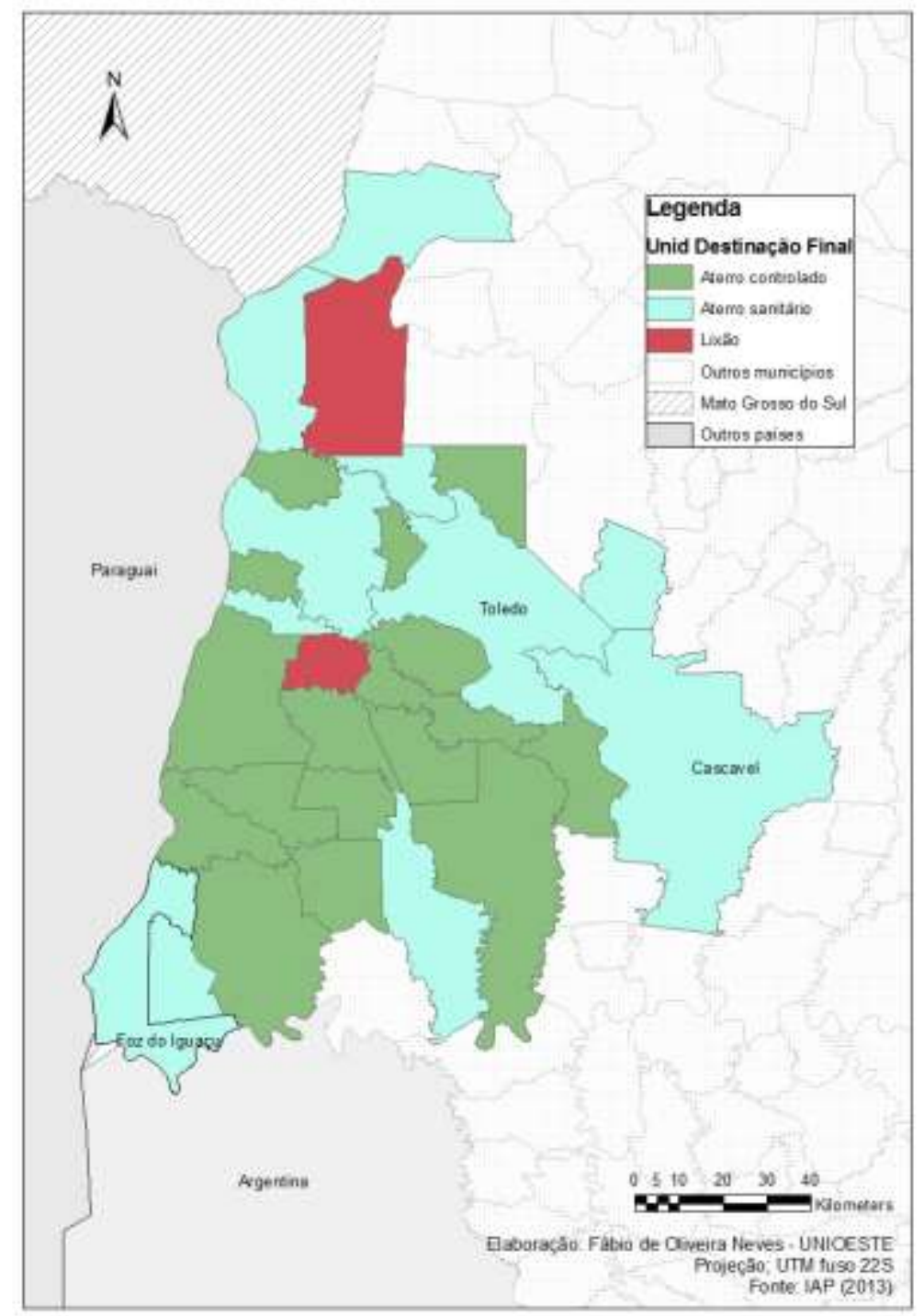

Figura 8: Unidades de destinação final de resíduos sólidos nos municípios da Bacia do Paraná III - 2012.

\footnotetext{
${ }^{11}$ Relatos presentes em Neves (2013).
} 
Nota-se uma situação relativamente positiva, com a instalação de aterros sanitários em 11 municípios. Embora, na maior parte deles ainda estejam em operação os aterros controlados. Somente em dois municípios há lixões em atividade. Nos municípios do grupo 1, os grandes produtores de resíduos, as condições de operação dos aterros sanitários são satisfatórias e de acordo com as normas ambientais (Resolução SEMA/IAP/SUDERSHA n. 01/2006). Dois deles, de Cascavel e de Toledo, possuem Renovação de Licença de Operação válida emitida pelo órgão ambiental responsável, o Instituto Ambiental do Paraná ${ }^{12}$.

Quanto às unidades de beneficiamento (reciclagem e/ou compostagem) presentes na Bacia do Paraná III, alguns municípios declararam para o SNIS a existência de galpões de triagem, entre eles, os três municípios do grupo 1. As atividades nesses equipamentos são, por vezes, caracterizadas por limitações de diversas naturezas, tanto o de pessoal disponível nas organizações de catadores para o trabalho quanto para conseguir beneficiar todo o material que chega aos galpões de triagem. A existência de instalação para a compostagem de resíduos sólidos urbanos, porém, só é indicada em Foz do Iguaçu. Trata-se de um espaço reservado no aterro sanitário do município que realiza a compostagem apenas de restos orgânicos do CEASA, conforme exposto em Neves (2013).

\section{CONSIDERAÇÕES FINAIS}

O panorama apresentado sobre a gestão dos resíduos sólidos urbanos na Bacia do Paraná III permite contribuir para a elaboração de uma agenda positiva de pesquisa nesse recorte territorial. Um conjunto de estudos ordenados e orientados por essa agenda pode municiar o processo de tomada de decisões, as políticas e programas adotados pelos poderes públicos.

\footnotetext{
${ }^{12}$ Licenças: $\mathrm{n}^{\circ}$. 8.225 para o aterro sanitário de Toledo e $\mathrm{n}^{\circ} .26 .058$ para a ampliação do aterro de Cascavel.
} 
Um primeiro elemento a ser considerado na Bacia do Paraná III é a forte concentração da produção dos resíduos sólidos em apenas três municípios: Cascavel, Foz do Iguaçu e Toledo. Estes respondem por $3 / 4$ dos resíduos coletados na área de estudo. O estudo detalhado sobre esses municípios e sobre a busca de soluções para os problemas do setor é central nessa agenda de pesquisa.

A inserção das empresas privadas no setor de limpeza pública também é elemento de destaque. Elas já respondem por $3 / 4$ dos resíduos coletados na Bacia do Paraná III, acompanhando o recurso à terceirização praticado na região Sul do Brasil. Devem, portanto, integrar a agenda, os estudos que envolvam as parcerias público-privadas e que busquem compreender como se comporta o "mercado" dos serviços públicos na área de estudo. Há mercado para as grandes empresas prestadoras de serviços nos pequenos municípios?

Os catadores, enquanto atores sociais e do meio ambiente urbano, têm papel relevante. Obtiveram avanços enquanto parceiros do poder público e no seu reconhecimento social. Não raramente passam a ser denominados de agentes ambientais. São reconhecidos como parceiros na execução da coleta de lixo em 19 municípios da Bacia do Paraná III. Em quase toda a área referida, existem organizações de catadores, associações e/ou cooperativas, que indicam a ocorrência do processo de empowerment desse ator, apoiado pelo poder público e por outros atores, como a Itaipu Binacional e seus programas ambientais e as Igrejas. Trata-se de um terceiro elemento incontornável para a composição da agenda.

É necessário também incluir, nesse elemento, a articulação em rede e o impacto do programa Cataforte na Bacia do Paraná III. Assim como reconhecer a influência da experiência de Foz do Iguaçu, do Programa Coleta Solidária, e da COAAFI nas demais experiências de organização dos catadores na região.

Um quarto elemento é a elaboração dos planos de gestão de resíduos sólidos e as perspectivas de planejamento de médio e longo prazo. Também é possível incluir, nesse sentido, as tentativas dos poderes 
públicos de atenderem as demandas da sociedade civil e de construírem uma governança do ambiente urbano que traga melhores resultados no setor dos resíduos sólidos.

É necessário questionar-se igualmente sobre a falta de impacto do projeto de Regionalização e formação de consórcios para a gestão de resíduos sólidos. Assim como a quase ausência de consórcios nesse setor e a inação do único consórcio que existe legalmente - o Consórcio Intermunicipal para Gerenciamento de Resíduos Sólidos do Oeste do Paraná, que envolve seis municípios da bacia hidrográfica e mais Palotina.

O problema da destinação final é o sexto elemento relevante. Os três municípios que mais concentram a produção de resíduos sólidos possuem aterros sanitários equipados e adequados à legislação estadual, garantindo ao menos uma eliminação adequada para $3 / 4$ do lixo urbano coletado na área de estudo. E com relação aos municípios pequenos? Quais são as dificuldades enfrentadas para instalar aterros sanitários e mantê-los?

É possível acrescentar mais um elemento: a interferência do meio físico na gestão dos resíduos sólidos. De que forma a localização dos municípios interfere nas opções adotadas ou a adotar para os serviços do setor? Existem entraves físico-naturais com consequências na prestação desses serviços e, principalmente, para a criação e manutenção de unidades de destinação final? Como a poluição proveniente do manejo dos resíduos sólidos e suas consequências impactam a opinião pública e influenciam a ação e o planejamento dos gestores?

Enfim, são muitos temas e a agenda está aberta. Todos esses temas são caros ao meio ambiente urbano e fazem parte da composição de outras agendas mais amplas: da Geografia Urbana, da Regional e dos problemas socioambientais.

\section{REFERÊNCIAS}

ANDRADE, R. M.; FERREIRA, J. A. A gestão de resíduos sólidos urbanos no Brasil frente às questões da Globalização. Rede - Revista eletrônica do 
PRODEMA, Fortaleza, v.6, n.1, p. 7-22, mar. 2011. Disponível em: $<$ http://www.revistarede.ufc.br/index.php/rede/article/viewArticle/118>. Acesso em: $17 / 4 / 2015$.

BARBIER, R. La fabrique de l'usager. Le cas de la collecte sélective des déchets, Flux, n. 48/49, p. 35-46, avril-septembre 2002.

BOLOGNESI, A. Incineração e aterro sanitário: uma comparação entre duas tecnologias. In: SANTOS, M. C. L.; DIAS, S. L. F. G. (Org.). Resíduos sólidos urbanos e seus impactos socioambientais. São Paulo: IEE/USP, 2012. p. 23-30.

BOSI, A. de P. A organização capitalista do trabalho "informal". O caso dos catadores de recicláveis. Revista Brasileira de Ciências Sociais, São Paulo, v.23, n. 67, p. 101-116, jun. 2008.

CAVÉ, J.; DELARUE, J.; DURAND, M.; LE BOZEC, A. Organisation de la valorisation des déchets dans les pays du Sud. Kit d'investigation et premiers terrains. Paris : Université du Maine (UMR ESO CNRS), 2015. 13 p. (Agence Française de Développement. Projet ORVA2D). Projeto em andamento.

FUNDAÇÃO ESTADUAL DO MEIO AMBIENTE. Orientações básicas para a operação de aterro sanitário. Belo Horizonte: FEAM, 2006.

GAILLOCHET, C. Du rare à l'infini: panorama mondial des déchets 2009. 3. ed. Paris: Economica, 2009.INSTITUTO AMBIENTAL DO PARANÁ. Relatório da situação atual da disposição final de resíduos sólidos urbanos no estado do Paraná (2012). Diretoria de Controle dos Recursos Ambientais. Curitiba, 2013.

IKUTA, F. A. Resíduos sólidos urbanos no Pontal do Paranapanema - SP: inovação e desafios na coleta seletiva e organização de catadores. Tese (Doutorado em Geografia), Unesp, Campus de Presidente Prudente, Faculdade de Ciências e Tecnologia, Presidente Prudente - SP, 2010.

INSTITUTO BRASILEIRO DE GEOGRAFIA E ESTATÍSTICA. Pesquisa Nacional de Saneamento Básico - 2008. IBGE: Departamento de População e Indicadores Sociais. Rio de Janeiro, 2010. 
KRULJAC, S. Public-private partnerships in solid waste management: sustainable development strategies for Brazil. Bulletin of Latin American Research, Malden-USA, v. 31, n. 2, p. 222-236, 2012.

LIMA, A. G. A bacia hidrográfica como recorte de estudos em Geografia Humana. Revista Geografia, Londrina, v. 14, n. 2, p. 173-183, jul./dez. 2005.

MEIRA, F. B. et al. Gestão ambiental com inclusão social: limites e (im)possibilidades. Análise da inserção das cooperativas de catadores no campo da indústria de reciclagem. Revista OLAM: ciência \& tecnologia, Rio Claro-SP, v.7, n.2, p. 244-265, dez. 2007.

NEVES, F. O. Gestão pública de resíduos sólidos urbanos: problemática e práticas de gestão no Oeste paranaense. Tese (Doutorado em Geografia), UFPR, Setor de Ciências da Terra, Curitiba-PR, 2013.

PIERRAT, A. Produire moins des déchets, trier à la source, est-ce envisageable au Sud? Revue Liaison Énergie-Francophonie, Québec, n. 90, p. 26-29, 4. trim. 2011.

ROCHER, L. Gouverner les déchets. Gestion territoriale des déchets ménagers et participation publique. Thèse (Doctorat en Aménagement de l'espace - Urbanisme). CITERES UMR CNRS, École Doctorale Sciences de l'Homme et de la Société, Université François Rabelais - Tours, 2006, $445 f$.

RUTKOWSKI, J. E. \& RUTKOWSKI, E. W. Expanding worldwide urban solid waste recycling: The Brazilian social technology in waste pickers inclusion. Waste Management \& Research, V. 33, n. 12, p. 1084-1093, 2015.

SISTEMA NACIONAL DE SANEAMENTO AMBIENTAL. Diagnóstico do manejo de resíduos sólidos urbanos - 2013. Brasília: Ministério das Cidades/SNSA, 2015.

TREMBLAY, C. \& GUTBERLET, J. Empowerment through participation: assessing the voice of leaders from recycling cooperatives in São Paulo, Brazil. Community Development Journal, Oxford, v. 47, n.2, p. 282-302, 2012. Disponível em: http://cdg.oxfordjournals.org. Acesso em: 15/4/2015. 